\title{
Quality of life and work ability of ovarian cancer patients in Slovakia
}

\author{
J. BIELIK ${ }^{1, *}$, B. BYSTRICKY ${ }^{2}$, K. HOFFMANNOVA ${ }^{3}$ V. MELUS ${ }^{1}$, I. MATISAKOVA ${ }^{1}$ \\ ${ }^{1}$ Faculty of Health Care, Alexander Dubcek University of Trencin, Trencin, Slovakia; ${ }^{2}$ Oncology Department, Faculty Hospital Trencin, Trencin, \\ Slovakia; ${ }^{3}$ Slovak Society for Pharmacoeconomics, Bratislava, Slovakia.
}

${ }^{*}$ Correspondence: jan.bielik@tnuni.sk

Received April 1, 2019 / Accepted June 19, 2019

\begin{abstract}
The aim of this paper was to find out the association of relevant factors on health-related quality of life (HRQOL) among ovarian cancer patients and their ability to work. Analyzed data were prospectively collected on 123 ovarian cancer patients enrolled across multiple oncology practices in Slovakia. We examined knowledge about the disease, negative perceptions related to health care, ability to work and social and economic ranking. HRQOL measurements included quality of life based on a numeric scale (1-worst, 10-best) and selected aspects from QoL-Ov28 questionnaire. We have used non-parametric Friedman and Dunne pairwise comparison tests to detect differences in HRQOL and the ability to work. Spearman correlation was used to measure the strength of association between variables. With hindsight, patients identified first signs of disease 3.6 months prior to diagnosis, with median duration of disease being 3.1 years. HRQOL was significantly different at various points during cancer journey; between current state and at diagnosis (4.19), between current state and at time without cancer or at time in full health (8.94, 9.52 respectively). Similarly, significant differences were noted in patients' current work ability (WA) compared to WA at diagnosis, or at time without cancer or in full health $(4.2,9.07,9.58)$. The highest correlation of HRQOL was found in relation to current ability to work $(r=0.87)$ and in impact of cancer treatment $(\mathrm{r}=0.66)$. Medium correlation was noted with visits to oncology clinics, knowledge about cancer, salary, future expectations or perceived quality of life of relatives $(r<0.51)$. Low correlation $(r<0.3)$ was found with other aspects related to healthcare (nursing care, general practitioner appointments) or demographics (age, number of children) and others. Patients were willing to pay monthly for curative treatment $€ 191.84$ from an average monthly salary $€ 470.84$ (41\%). Ovarian cancer diagnosis has a significant impact on HRQOL and WA and both are positively highly correlated. Ovarian cancer patients are willing to give significant share of their monthly salary for treatment leading to cure.
\end{abstract}

Key words: ovarian cancer, health-related quality of life (HRQOL), ability to work, willingness to pay

Ovarian cancer is the $7^{\text {th }}$ most common cancer in women; with over 230,000 new patients diagnosed yearly worldwide [1]. It is associated with the highest mortality of all gynecological cancers in the developed world and is the fifth leading cause of all cancer-related deaths among women. Primary treatment is optimal debulking surgery, followed by chemotherapy. Despite the high initial responses, most patients experience relapse with diminishing effectiveness and an increase in the toxicity of subsequent treatments. Dominant symptoms of ovarian cancer patients are abdominal discomfort, pain, ascites or altered bowel movements. One important aspect is that the disease course involves radical surgery and intense courses of chemotherapy, i.e. health-related quality of life (HRQOL) is often compromised [2]. There is important evidence that an improvement in appetite, constipation and global health scores during the first 3 months of treat- ment is significantly associated with improved survival time in ovarian cancer [3]. HRQOL in ovarian cancer patients was investigated in several studies [4-10]. Initial studies focused more on psychological symptoms. In ovarian cancer patients, depression was found in $21 \%$ and anxiety in 29\% [4-6]. These were positively associated with performance status and features of HRQOL [11]. Further studies undertook a more complex evaluation of the quality of life (QoL), including psychological, physical and social domains [7-10]. A recent review of existing literature showed that ovarian cancer and its treatment have significant effects on QoL including fatigue and the physical and functional domains [12]. Reviewed studies indicate that ovarian cancer patients need a QoL change during the trajectory of the disease. Impact of disease duration and treatment on HRQOL together with patientrelated outcomes (PROs) become regular feature of studies 
on quality of life in oncology patients. The latest systematic review of 31 studies on HRQOL found that a majority of patients with ovarian cancer (OC) experience fatigue and depression, have more somatic and mental morbidity, and use the medication and health services more than healthy controls [13]. Interestingly, OC survivors tended to have stronger and positive relationships with significant others than healthy controls. A meta-analysis of 30 randomized EORTC trials, including two in ovarian cancer, on baseline quality of life revealed that HRQOL scales can provide prognostic information beyond clinical and sociodemographic variables [14]. Given the current economic climate, rising out-of-pocket expenses and drug pricing, we have also incorporated patients' ability to work and willingness to pay into our cross-sectional HRQOL study in OC patients.

\section{Patients and methods}

We have conducted a cross-sectional survey on HRQOL in the pilot and expanded population of a total of 123 ovarian cancer patients identified by treating oncologists as being able to complete the questionnaire either alone or with the assistance of oncology liaison nurses. General inclusion criteria were women aged 18 years and older, diagnosis of ovarian cancer, performance status permitting to complete all questions and signed informed consent. Both pilot and expanded cohort questionnaires were similar (Suppl data S1). The pilot cohort included additional questions from EORTC QoL-Ov28 (Suppl data S2) in the expanded cohort, queries regarding histology, treatment and stage went into more detail. Self-administered questionnaires were based on PRO and included demographics, cancer stage, awareness of the disease, comorbidities, and perceptions regarding the health care delivery, quality of life, ability to work, socioeconomic status as well as future expectations. Descriptive statistics, i.e. the mean and the standard deviation were calculated for quantitative data. We have used non-parametric Friedman and Dunne pairwise comparison tests to detect differences in HRQOL and the ability to work. Spearman correlation was used to measure the strength of association between variables [15]. A p-value $<0.05$ was considered as statistically significant. Data were analyzed using Statistica for Windows 5.0 (StatSoft Inc., Tulsa, OK, USA).

\section{Results}

General characteristics. A total of 123 OC patients completed the self-administered questionnaire. Mean age, weight and height were 59.7 years, $70.3 \mathrm{~kg}$ and $163 \mathrm{~cm}$, respectively. Basic education completed 33 (26.8\%) patients, middle school 72 (58.5\%) and college/university 18 (14.7\%) patients. Regarding marital status, $10(8.2 \%)$ patients were single, 75 married with 4 (64.2\%) living in common household with a partner, $26(21.1 \%)$ were widowed and 8 (6.5\%) were divorced. Mean parity in our cohort was 2 children.
At this time $12(9.8 \%)$ patients were smoking and regular alcohol use admitted $11(8.9 \%)$ patients. Out of all respondents, $42(34.1 \%)$ were currently employed, 3 (2.4\%) were unemployed, and 60 (48.8\%) were retired (social pensioners) plus 18 (14.7\%) were disabled retirees (disability pensioners). Four patients from the whole cohort of 123 patients did not fill completely the QoL data and three patients did not fill completely the work ability (WA) data. This fact did not have any impact on final results in evaluation of the QoL and WA, so they were included in the whole evaluated sample.

Clinical characteristics and selected symptoms. Most patients were in stage III, metastatic disease was present in 17 patients (13.8\%); commonly in liver, lungs and distant lymph nodes. Patients were diagnosed at mean 3.13 years before completing the survey, and with hindsight, patients identified first signs of the disease 3.6 months prior to the diagnosis. Each year, the patients spent on average 1.8 months as in-patients in hospital; they visited their oncologist on average 5.7 times, gynecologist 3.3 times, respiratory physician 1.7 times and GP 4.7 times. The most common comorbidities were hypertension (53-43.1\%), diabetes (19-15.4\%), back pain (13-10.6\%), coronary heart disease (11-8.9\%), rheumatologic disorders and others. Selected symptoms from QoL-Ov28 questionnaire were surveyed with mean values (1-no symptoms, 4 -worst symptoms) for abdominal pain 1.45 , bloating 1.53 , fullness after meal 1.51 , hair loss 2.46, upset by hair loss 2.2, tingling in hands or feet 2.19 , weakness 2.5 and hot flushes 1.65 .

Health care delivery, the impact of disease and future expectations. Patients were informed about their disease on average at 4.06 (1-worst, 5-best) with the most information having from the treating oncologist and from the internet. Satisfaction with a health care delivery by a physician was at 4.48 and by a nurse at 4.46 (1-worst, 5 -best). Negative factors regarding health care delivery and use were the lack of psychological support (19 patients), appointment scheduling and waiting (15), financial expenditure (8) and others. When asked to self-rank on scale 1-pessimist to 5-optimist, patients were more optimistic, ranked on average at 3.58. Similarly, their future expectations were ranked at 3.79. The most optimistic outlook had family future (4.16), followed by health (3.59), finances (3.26) and future work (3.16).

Quality of life and work ability. The quality of life (1-worst, 10-best) of OC patients ranked at different time points in their life, currently at 6.98 , at OC diagnosis 4.12 , at the time without OC at 8.96 and at full health 9.53. Current work ability patients ranked at 6.22 , at OC diagnosis 4.20 , at the time without OC at 9.07 and at full health 9.58. The impact that OC treatment has on their QoL was ranked at 6.33, the impact of religion on QoL at 6.91 and the impact of OC diagnosis at QoL of their family at 6.11 (1-worst, 10-best).

Social and economic domains. Expenses for travel, drugs and physician visits dominated in spending for cancer diagnosis, compared to drugs and travel in other medical conditions. Monthly expenditure for ovarian cancer 
(compared to all expenditures in other comorbidities, such as hypertension, diabetes or back pain), were more prominent; for drugs $€ 63$ vs $€ 49$, physician visits $€ 28$ vs $€ 5$, other tests $€ 7$ vs none, travel $€ 77$ vs $€ 27$, loss of the income $€ 25$ vs none, other expenses $€ 15$ vs $€ 9$. In total, monthly expenses for OC were doubled compared to other health conditions (€215 vs €90). On average, OC patients were on sick-leave for 36 days/year due to their cancer-related conditions, compared to 5.8 days for other illnesses (such as hypertension, diabetes or back pain). Patients were willing to pay monthly for curative treatment $€ 191.84$ from an average monthly salary €470.84 (41\%).

Statistical comparisons for HRQOL. We have compared HRQOL at different time points in relation to OC diagnosis using nonparametric Friedman (Table 1) test with the subsequent Dunn's (Table 2) pairwise comparison test. All comparisons were statistically significant with $\mathrm{p}<0.001$. Similar results were obtained for the work ability. Significant differences in the work ability were confirmed at different time points during the patient cancer journey. These were also significant when compared to one another using Dunne pairwise comparison (Table 3, Table 4). We have also used Spearman nonparametric correlation coefficient to test the relationship (correlation) of the selected factors with current HRQOL [15]. No correlation was detected with education $(-0.02)$, faith $(+0.04)$, stage of OC $(-0.04)$, loss of income $(+0.07)$. Small correlation was detected in nursing care $(-0.15)$, parity $(-0.18)$, GP visits $(-0.18)$, physician care $(-0.20)$, alcohol consumption $(-0.24)$, disease duration $(+0.28)$, age $(-0.29)$ and personality $(+0.29)$. Medium correlation, up to +0.51 was detected for oncologist visits $(-0.38)$, information about the disease $(+0.40)$, salary $(+0.42)$, future expectations $(+0.41)$ and quality of the family life $(+0.51)$. The strongest correlation was detected in the impact of cancer treatment $(+0.66)$ and a current work ability $(+0.87)$.

\section{Discussion}

In our cross-sectional HRQOL study on OC patients and survivors, we have chosen selected questions from validated QLQ-Ov28 [16]. We use the words "work ability" which partially covered dimensions EQ 5D questionnaire "mobility, self-care and usual activities" [17]. In addition, we have relied on PROs as a useful assessment of patients' treatment and interaction with healthcare. Baseline scores from this study are in line with HRQOL reports from other ovarian cancer patients, where significant emphasis from patients was given to the body image (hair loss) and the impact of a treatment (neuropathy, fatigue) $[18,19,11]$. Psychological factors were also emphasized in health care delivery questions, where the lack of psychological support was most commonly cited. Nonetheless, OC patients retained an optimistic attitude towards their and family future. These findings provide additional data to inform areas of priority for OC patients. OC patients from our cohort had spent on average almost 2
Table 1. Comparing HRQOL at different time points in OC patients' journey.

\begin{tabular}{|c|c|c|c|c|c|c|c|}
\hline HRQOL & $\mathbf{n}$ & $\overline{\mathbf{x}}$ & $\mathbf{x}_{\mathrm{m}}$ & $\min$ & $\max$ & sd & p-value \\
\hline Currently & 119 & 6.98 & 8 & 0 & 10 & 2.41 & \multirow{4}{*}{$<0.001$} \\
\hline At OC diagnosis & 119 & 4.19 & 4 & 0 & 10 & 2.43 & \\
\hline At time without OC & 119 & 8.94 & 9 & 4 & 10 & 1.36 & \\
\hline At full health & 119 & 9.52 & 10 & 5 & 10 & 0.85 & \\
\hline
\end{tabular}

$\mathrm{n}$ - number of patients, $\overline{\mathrm{x}}$ - mean, $\mathrm{x}_{\mathrm{m}}$ - median, sd - standard deviation, p - probability level of the Friedman test. Note: 4 patients from 123 patients did not fill completely the QoL data.

Table 2. Pairwise comparison of HRQOL at different time points in OC patients' journey.

\begin{tabular}{lcccc}
\hline & Currently & $\begin{array}{c}\text { At OC } \\
\text { diagnosis }\end{array}$ & $\begin{array}{c}\text { At time } \\
\text { without OC }\end{array}$ & $\begin{array}{c}\text { At full } \\
\text { health }\end{array}$ \\
\hline Currently & - & $<0.001$ & $<0.001$ & $<0.001$ \\
At OC diagnosis & $<0.001$ & - & $<0.001$ & $<0.001$ \\
At time without OC & $<0.001$ & $<0.001$ & - & $<0.01$ \\
At full health & $<0.001$ & $<0.001$ & $<0.01$ & - \\
\hline
\end{tabular}

Analysis using Dunn's pairwise comparison test, the given values are Dunn's test p-values.

Table 3. Comparing work ability at different time points in OC patients' journey.

\begin{tabular}{lccccccc}
\hline Work ability & $\mathbf{n}$ & $\overline{\mathbf{x}}$ & $\mathbf{x}_{\mathrm{m}}$ & $\boldsymbol{m i n}$ & $\mathbf{m a x}$ & $\mathbf{s d}$ & p-value \\
\hline Currently & 120 & 6.22 & 7 & 0 & 10 & 3.13 & \\
At OC diagnosis & 120 & 4.20 & 4 & 0 & 10 & 2.65 & \\
At time without OC & 120 & 9.01 & 10 & 3 & 10 & 1.32 & $<0.001$ \\
At full health & 120 & 9.58 & 10 & 5 & 10 & 0.09 & \\
\cline { 1 - 4 }
\end{tabular}

Three patients were excluded due to data incompleteness. $\mathrm{n}$ - number of patients, $\overline{\mathrm{x}}$ - mean, $\mathrm{x}_{\mathrm{m}}$ - median, sd - standard deviation, $\mathrm{p}$ - probability level of the Friedman test. Note: 3 patients from 123 patients did not fill completely the WA data.

Table 4. Pairwise comparison of HRQOL at different time points in OC patients' journey.

\begin{tabular}{lcccc}
\hline & Currently & $\begin{array}{c}\text { At OC } \\
\text { diagnosis }\end{array}$ & $\begin{array}{c}\text { At time } \\
\text { without OC }\end{array}$ & $\begin{array}{c}\text { At full } \\
\text { health }\end{array}$ \\
\hline Currently & - & $<0.001$ & $<0.001$ & $<0.001$ \\
At OC diagnosis & $<0.001$ & - & $<0.001$ & $<0.001$ \\
At time without OC & $<0.001$ & $<0.001$ & - & $<0.05$ \\
At full health & $<0.001$ & $<0.001$ & $<0.05$ & - \\
\hline
\end{tabular}

Analysis using Dunn's pairwise comparison test, the given values are Dunn's test p-values.

months per year in a hospital. This extensive use of in-patient services might reflect the complication of cancer diagnosis, comorbidities as well as generally high hospital utilization in Central and Eastern Europe. From a recent EU report, Slovakia placed in the top ten countries with almost 200 hospital discharges per 1,000 inhabitants [20]. Across EU countries, the main conditions leading to hospitalizations were cardio- 
vascular, digestive and obstetric conditions as well as cancer. Ovarian cancer diagnosis has a significant impact on QoL and work ability at the time of diagnosis and with successful treatment is this negative impact only partially reversed [ 18 , $19,8]$. This is underlined by the fact that only $15 \%$ of ovarian cancer cases were diagnosed at an early stage and in general, the 5-year survival rate was only $46 \%$ [21]. The clinical state had an impact on mobility impairment and is associated with medical comorbidities, abdominal bloating, fatigue, lack of appetite, numbness/tingling, and pain [22]. The other impact is on disability to work, and this could be expressed as DALY (disability adjusted life years). Ovarian cancer was on the fourth place of malignant diseases in females in relationship to DALY-s, behind the breast, cervical, and lung cancer [23]. This highlights the fact that OC survivors may benefit from additional resources and interventions, beyond that provided by a treating oncologist. The strongest positive correlation to HRQOL in OC patients was with the work ability, the impact of cancer treatment, future expectations, QoL of family, salary and information about the disease. It is clear that patients value not only productive working and earnings but also care about the burden on their family and future prospects. A systematic review of randomized trials of HRQOL in OC patients found that survivors tended to have a more positive relationship with their partners compared to controls [24]. Moreover, the family costs associated with informal caregiving to ovarian cancer patients in Italy from diagnosis up to the end of first line chemotherapy have been estimated at $€ 10,981$ annually [25]. In our study, we have found more pronounced spending for OC diagnosis (€215) compared to other health issues (€90). Ovarian cancer patients were prepared to spend $41 \%$ of their monthly salary for curative treatment. As significant out-of-pocket expenses are required for OC patients, it is important to note that lower financial status was associated with deteriorating of QoL in Chinese OC patients [19]. To the best of our knowledge, this is the first study in OC patients from Central and Eastern Europe assessing factors associated with HRQOL, including the ability to work and willingness to pay. There are several limitations to our study. First, it was a cross-sectional study with a relatively small number of participants. However, patients were recruited from several oncology practices across the country. This was a pilot study, our sample represents about 4 to $5 \%$ of ovarian cancer prevalence in Slovakia with similar average stage $[26,27]$. The aim of this study was to identify general trends and statistically significant correlations should be interpreted in this context. Secondly, a mixed population of OC patients with different histologies and stages was included. Yet, this population represents the true OC population in oncology out-patient departments. We are also conscious of the limitations by administering the investigator-derived questionnaire. Nonetheless, additional needs of patients were captured by using the patient reported outcomes. This study reveals significant differences between HRQOL and the ability to work in ovarian cancer survivors.
Our findings suggest that HRQOL was significantly different at various points during the cancer journey; between the current state and at the diagnosis and at the time without cancer or at the time in full health. Similarly, significant differences were noted in the patients' work ability. The highest correlation of HRQOL was found in relation to the current ability to work and in the impact of cancer treatment. These domains should be the priority areas for future studies and interventions.

Supplementary information is available in the online version of the paper.

Acknowledgments: We thank participating oncologists: Dr. Packan (Kosice), Dr. Sufliarsky (Bratislava), Dr. Salek (Bratislava), Dr. Helpianska (Bratislava), Dr. Spanik (Bratislava), Dr. Johnova (Banska Bystrica), Dr. Stykova (Banska Bystrica).

\section{References}

[1] FERLAY J, SOERJOMATARAM I, ERVIK M, DIKSHIT R, ESER S et al (Eds.). GLOBOCAN 2012. Estimated Cancer Incidence, Mortality and Prevalence Worldwide in 2012 v1.0. IARC CancerBase No. 11. ISBN 978-92-832-2447-1. [http://globocan.iarc.fr]

[2] CHASE DM, WENZEL L. Health-related quality of life in ovarian cancer patients and its impact on clinical management. Expert Rev Pharmacoecon Outcomes Res 2011; 11: 421-431. https://doi.org/10.1586/erp.11.41

[3] GUPTA D, BRAUN DP, STAREN ED, MARKMAN M. Longitudinal health-related quality of life assessment: implications for prognosis in ovarian cancer. J Ovarian Res 2013; 6: 17. https://doi.org/10.1186/1757-2215-6-17

[4] FERRELL B, SMITH SL, CULLINANE CA, MELANCON C. Psychological well being and quality of life in ovarian cancer survivors. Cancer 2003; 98: 1061-1071. https://doi. org/10.1002/cncr.11291

[5] NORTON TR, MANNE SL, RUBIN S, CARLSON J, HERNANDEZ E et al. Prevalence and predictors of psychological distress among women with ovarian cancer. J Clin Oncol 2004; 22: 919-926. https://doi.org/10.1200/JCO.2004.07.028

[6] STEWART DE, WONG F, DUFF S, MELANCON CH, CHEUNG AM. "What doesn't kill you makes you stronger": an ovarian cancer survivor survey. Gynecol Oncol 2001; 83: 537-542. https://doi.org/10.1006/gyno.2001.6437

[7] TENG FF, KALLOGER SE, BROTTO L, MCALPINE JN. Determinants of quality of life in ovarian cancer survivors: a pilot study. J Obstet Gynaecol Can 2014; 36: 708-715. https://doi.org/10.1016/S1701-2163(15)30513-2

[8] GREIMEL E, DAGHOFER F, PETRU E. Prospective assessment of quality of life in long-term ovarian cancer survivors. Int J Cancer 2011; 128: 3005-3011. https://doi.org/10.1002/ ijc. 25642

[9] MIRABEAU-BEALE KL, KORNBLITH AB, PENSON RT, LEE H, GOODMAN A et al. Comparison of the quality of life of early and advanced stage ovarian cancer survivors. Gynecol Oncol 2009; 114: 353-359. https://doi.org/10.1016/j. ygyno.2009.05.009 
[10] KORNBLITH AB, MIRABEAU-BEALE K, LEE H, GOODMAN AK, PENSON RT et al. Long-term adjustment of survivors of ovarian cancer treated for advanced-stage disease. J Psychosoc Oncol 2010; 28: 451-469. https://doi.org/10.1080 /07347332.2010.498458

[11] BODURKA-BEVERS D, BASEN-ENGQUIST K, CARMACK CL, FITZGERALD MA, WOLF JK et al. Depression, anxiety, and quality of life in patients with epithelial ovarian cancer. Gynecol Oncol 2000; 78: 302-308. https://doi. org/10.1006/gyno.2000.5908

[12] ARRIBA LN, FADER AN, FRASURE HE, VON GRUENIGEN VE. A review of issues surrounding quality of life among women with ovarian cancer. Gynecol Oncol 2010; 119: 390-396. https://doi.org/10.1016/j.ygyno.2010.05.014

[13] AHMED-LECHEHEB D, JOLY F. Ovarian cancer survivors' quality of life: a systematic review. J Cancer Surviv 2016; 10: 789-801. https://doi.org/10.1007/s11764-016-0525-8

[14] QUINTEN C, COENS C, MAUER M, COMTE S, SPRANGERS MA et al. Baseline quality of life as a prognostic indicator of survival: a meta-analysis of individual patient data from EORTC clinical trials. Lancet Oncol 2009; 10: 865-871. https://doi.org/10.1016/S1470-2045(09)70200-1

[15] SNEDECOR GW, COCHRAN WG (Eds.). Statistical Methods, $8^{\text {th }}$ Edition. Iowa State University Press, 1989, p. 503. ISBN: 978-0813815619.

[16] CULL A, HOWAT S, GREIMEL E, WALDENSTROM AC, ARRARAS J et al. Development of a European Organization for Research and Treatment of Cancer questionnaire module to assess the quality of life of ovarian cancer patients in clinical trials: a progress report. Eur J Cancer 2001; 37: 47-53. https://doi.org/10.1016/s0959-8049(00)00369-5

[17] EUROQOL GROUP. EuroQol - a new facility for the measurement of health-related quality of life. Health Policy 1990; 16: 199-208. https://doi.org/10.1016/0168-8510(90)90421-9

[18] MERANER V, GAMPER EM, GRAHMANN A, GIESINGER JM, WIESBAUER P et al. Monitoring physical and psychosocial symptom trajectories in ovarian cancer patients receiving chemotherapy. BMC Cancer 2012, 12: 77. https:// doi.org/10.1186/1471-2407-12-77
[19] STAVRAKA C, FORD A, GHAEM-MAGHAMI S, CROOK T, AGARWAL R et al. A study of symptoms described by ovarian cancer survivors. Gynecol Oncol 2012; 125: 59-64. https://doi.org/10.1016/j.ygyno.2011.12.421

[20] OECD, EU. Health at a Glance: Europe 2018. State of Health in the EU Cycle. OECD Publishing, Paris, EU, Brussels 2010. https://doi.org/10.1787/health_glance_eur-2018-en

[21] AMERICAN CANCER SOCIETY. Cancer Facts \& Figures 2010. American Cancer Society, Atlanta 2010, No 500810, p 68.

[22] CAMPBELl G, HAGAN T, GILBERTSON-WHite S, HOUZE M, DONOVAN H. Cancer and treatment-related symptoms are associated with mobility disability in women with ovarian cancer: A cross-sectional study. Gynecol Oncol 2016; 143: 578-583. https://doi.org/10.1016/j.ygyno.2016.09.013

[23] AIHW. Burden of Cancer in Australia: Australian Burden of Disease Study 2011. Australian Institute of Health and Welfare, Canberra 2017, Cat. no. BOD 13, p. 135.

[24] ANGIOLI R, CAPRIGLIONE S, ALOISI A, MIRANDA A, DE CICCO NARDONE $C$ et al. Economic Impact Among Family Caregivers of Patients With Advanced Ovarian Cancer. Int J Gynecol Cancer 2015; 25: 1541-1546. https://doi. org/10.1097/IGC.0000000000000512

[25] SHAO Z, ZHU T, ZHANG P, WEN Q, LI D, WANG S: Association of financial status and the quality of life in Chinese women with recurrent ovarian cancer. Health Qual Life Outcomes 2017; 15: 144. https://doi.org/10.1186/s12955-0170714-9

[26] ONDRUSOVA M, SADOVSKY O, PSENKOVA M. [Epidemiology of selected gynaecological malignancies in Slovakia.] Onkologia (Bratisl.) 2015; 10: 223-225.

[27] HLODAKOVA V, DIBA CS (Eds.). Cancer incidence in the Slovak Republic 2011. National Health Information Center, NOR, Bratislava 2018, p. 198. ISBN 978-80-89292-64-6. 


\title{
Quality of life and work ability of ovarian cancer patients in Slovakia
}

J. BIELIK ${ }^{1, *}$, B. BYSTRICKY ${ }^{2}$, K. HOFFMANNOVA ${ }^{3}$, V. MELUS $^{1}$, I. MATISAKOVA $^{1}$

\section{Supplementary Information}

\author{
Faculty of HealthCare, Alexander Dubcek University of Trencin, Slovakia \\ Quality of life and Health Economy Questionnaire
}

A. Demographic part

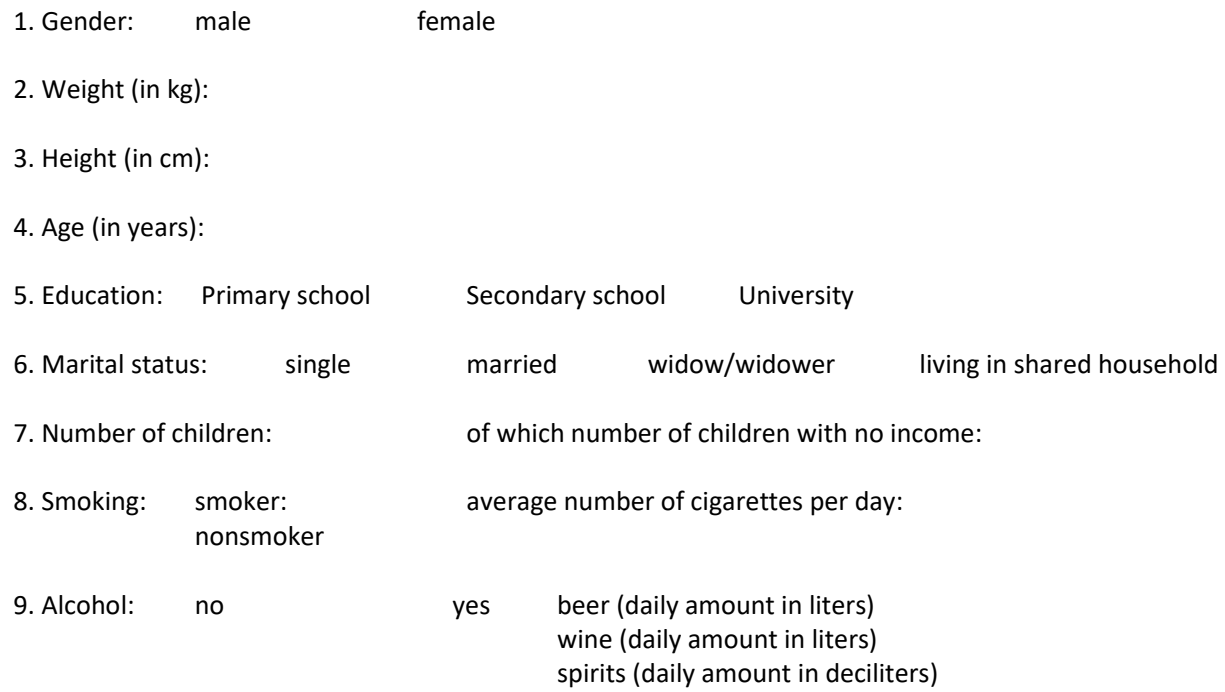

B. Clinical part

B1. Filled out by healthcare worker (physician)

1. Stage of cancer.

FIGO stage: I (ovaries) II (+pelvis) III (peritoneum)

Lymph nodes regionall with metastases yes no

Metastasis

yes

no

If yes (also number)

lungs

intrathoracic lymph nodes

liver

other (specify)

2. What treatment was applied?

surgical yes no

If yes, what type of intervention:

surgery was without any residue? yes no

chemotherapy yes no

If yes, indicate original name and (approximate) cumulative dose/number of cycles

Suppl. Table 1. Quality of life and Health Economy Questionnaire 


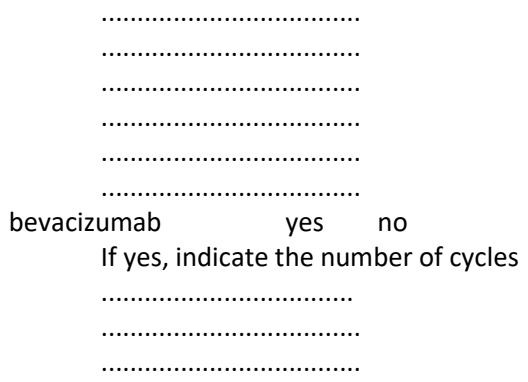

\section{B2. Filled out by the patient}

1. How long is it since the diagnosis of the disease?

number of years

number of months

2. How long before diagnosis did you experience symptoms of the disease?

number of years

number of months

4. Were you hospitalized because of the disease or attended a spa? - if yes, how many times in the last year?
no
yes number of hospitalizations in the last year
yes number of spa visits in the last year

5. Due to this disease, how many times a year on average do you visit:

oncologist

number of visits

pulmonologist

number of visits

general practitioner

number of visits

other physician number of visits

6. What medication and in what daily dosage is prescribed to you for this disease?

Medication
Medication
Medication
Medication

7. Do you take any other medications for this disease than the ones prescribed by your physician, e.g. medication that can be bought over the counter in pharmacies (other than homeopathic medicines)? If yes indicate the name of the medicine.

never occasionally often always

8. Do you take homeopathic medicines for this disease? If yes, indicate the name of the medicine.

never occasionally often always

9. Do you take any dietary supplements for this disease? If yes, indicate the name of the supplements.

never occasionally often always

Suppl. Table 1. Continued... 
10. Do you take any medication from herbs or any teas for this disease? If yes, indicate the name.

never occasionally often always

11. How would you rate how well are you informed about your disease

poor fair mediocre good excellent

12. From what sources did you gain most valuable knowledge about your disease?

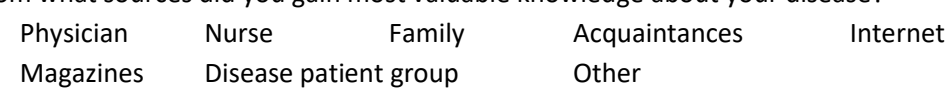

13. How would you rate the care provided to you by the physician regarding this disease? poor fair mediocre good excellent

14. How would you rate the care provided to you by the nurse regarding this disease? poor fair mediocre good excellent

15. Which area of healthcare do you perceive as the most negative in connection to this disease? If yes, you can indicate multiple answers.
a) yes $\square$
b) none

a1) appointment scheduling system

a2) attitude of the health care staff

a3) financial burden

a4) social care

a5) rehabilitation care

a6) psychological care

a7) other area

specify

16. How many years have you been treated for other diseases? You can indicate multiple answers.

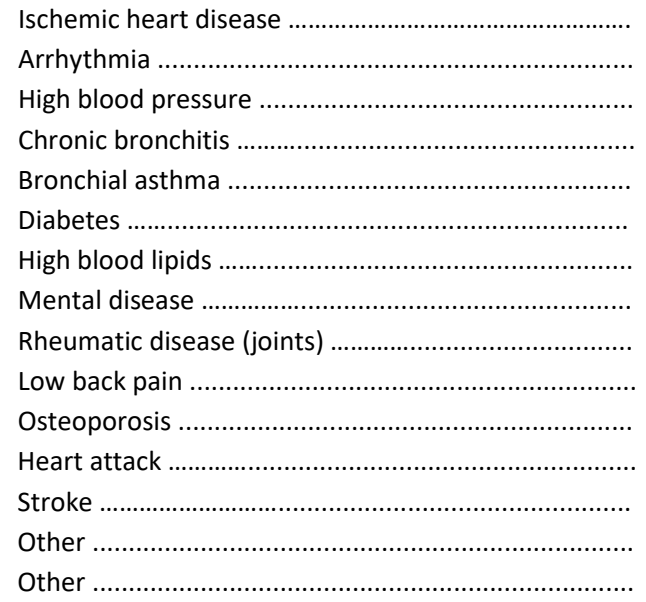

Ischemic heart disease

Chronic bronchitis

Bronchial asthma

Diabetes

High blood lipids

Mental disease

Rheumatic disease (joints)

Osteoporosis

Heart attack

Other number of years

number of years

number of years

number of years

number of years

number of years

number of years.

number of years

number of years

number of years

number of years

number of years

number of years

number of years

number of years

Suppl. Table 1. Continued ... 


\section{Quality of life}

\section{A. Quality of life}

1. How would you rate your current quality of life? (worst- 0 , best -10 )

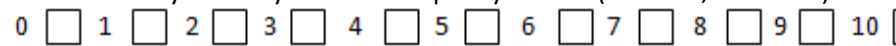

2. How would you rate your quality of life at the time of diagnosis of your disease? (worst- 0 , best -10 )
0
$1 \square 2 \square 3$
4
6
$8 \square 9 \square 10$

3. How would you rate your quality of life at times you were without this disease? (worst- 0 , best -10 )
0

4. How would you rate your quality of life at times you felt absolutely healthy? (worst- 0 , best -10 )
$0 \square 1 \square 2 \square 3$
$4 \square 5$
$6 \square 7$
$8 \square 9 \square 10$

\section{B. Ability to work}

5. How would you rate your current ability to work? (worst- 0 , best -10 )

$0 \square 1 \square 2 \square 3 \square 4 \square 5 \square 6 \square 7 \square 8 \square 9 \square 10 \square$

6. How would you rate your ability to work at the time of diagnosis of your disease? (worst- 0 , best -10 )
0 $1 \square 2 \square 3$
$4 \square 5$
$6 \square 7$
$8 \square 9 \square 10$

7. How would you rate your ability to work at times you were without this disease? (worst- 0 , best -10 )
$0 \square 1$
$\square 2 \square 3$
$4 \square 5$
$6 \square 7$
$8 \square 9 \square 10$

8. How would you rate your ability to work at times you felt absolutely healthy? (worst- 0 , best -10 )
0 $1 \square 2 \square 3 \square$
$4 \square 5$
$6 \square 7$ $8 \square 9 \square 10$

\section{Impact of the disease on quality of life of the patient and family}

9. How would you rate the impact of treatment on your quality of life since diagnosis? (worst- 0 , best -10 )
0 (

$4 \square 5 \square$

\author{
6
}

$7 \square 8$
$\square 9 \square 10$

10. How would you rate the impact of your disease on quality of life of your close relatives who you share a household with? (worst- 0 , best -10 )
$0 \square 1 \square 2 \square 3$
$4 \square 5$
$6 \square 7$
8
$9 \square 10$

\section{Impact of religious beliefs on quality of life of the patient}

11. How would you rate the impact of religious beliefs on your quality of life? (worst- 0 , best -10 )
$0 \square 1 \square 2 \square 3$
$4 \square 5$
$6 \square 7$
$8 \square 9 \square 10$

Suppl. Table 1. Continued ... 


\section{E. Personality type and expectations for the future}
12. Personality type: pessimist more of a pessimist both optimist and pessimist more of an optimist optimist

13. Expectations for the future:

\begin{tabular}{|l|l|l|l|l|l|}
\hline Expectations & Very bad & Quite bad & Neutral & Quite good & Very good \\
\hline Health & & & & & \\
\hline Economic & & & & & \\
\hline Work & & & & & \\
\hline Family & & & & & \\
\hline Total & & & & & \\
\hline
\end{tabular}

\section{Social-economic part}

1. Your social state:
a) employed
b) unemployed
c) age pension
d) health pension due to:

basic disease (..............................) other disease:
partial health pension due to:
e) partial health pension due to: basic disease (...............................) other disease:

2. Number of days on sick leave due to basic disease during last 12 months:

3. Number of days on sick leave due to other diseases during last 12 months:

4. Did any change occur in your social life due to this disease?
yes partially
no

If yes or partially yes, you can indicate more answers.

If yes or partially, please describe the change:

a, in family (worsening of relationships, divorce, etc.)

b, in work (e.g. reassignment to a different position, loss of employment etc.)

$c$, social life (e.g. loss of social status etc.)

d, in interests (e.g. limited or lost interests/hobbies/)

5. Did any change occur in your social life due to other diseases?

$$
\text { yes partially no }
$$

If yes or partially, you can indicate more answers.

If yes or partially, please indicate the disease and describe the change:

a, in family (worsening of relationships, divorce, etc.): Disease

b, in work (e.g. reassignment to a different position, loss of employment etc.): Disease

c, social life (e.g. loss of social status etc.): Disease

d, in interests (e.g. limited or lost interests/hobbies/): Disease... 
6. Loss of monthly income due to this disease (a very important question for the evaluation of economic burden of the disease): You can indicate more answers.
a, for medications
$b$, for physician visit
c, for other examinations
d, for transportation
e, for lower wage
$f$, for financial "incentives" for the physician or nurse
d, for other expenses

7. Loss of monthly net income due to other diseases (a very important question for the evaluation of economic burden of diseases): You can indicate more answers.
a, for medications:
b, for physician visit:
disease
$c$, for other examinations:
disease
d, for transportation:
disease
e, for lower wage:
disease
disease ........................
$f$, for financial "incentives" for the physician or nurse: disease
d, for other expenses:
disease .

8. Your current monthly net income (pension) in euro (a very important question for the evaluation of economic burden of the disease):

9. How much money would you be willing to sacrifice monthly for a permanent cure of this disease considering your current financial situation?

\section{F. Selected questions from EORTC QOL-OV28} In the last week:

1. Did you have abdominal pain?

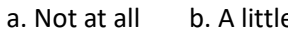
c. A lot
d. A significant amount

2. Dis you have bloated feeling in your stomach?
a. Not at all
b. A little
c. A lot
d. A significant amount

3. Did you feel "full" fast during meals?
a. Not at all
b. A little
c. A lot
d. A significant amount

4. Did you lose your hair?
$\begin{array}{lll}\text { a. Not at all b. A little } & \end{array}$
c. A lot
d. A significant amount

5. If yes - how much did the hair loss affect you?
a. Not at all b. A little
c. A lot
d. A significant amount

6. Did you experience numbness of fingers on your hands and toes?
a. Not at all
b. A little
c. A lot
d. A significant amount
7. Did you feel weak?
a. Not at all
b. A little
c. A lot
d. A significant amount

8. Did you experience hot flashes/sweating?
a. Not at all
b. A little
c. A lot
d. A significant amount

Suppl. Table 1. Continued... 


\section{European Organization for Research and Treatment of Cancer: Quality of life questionnaire-OV28}

\begin{tabular}{|c|c|c|c|c|}
\hline During the past week & Not at all & A little & Quite a bit & Very much \\
\hline 31. Did you have abdominal pain? & 1 & 2 & 3 & 4 \\
\hline 32. Did you have a bloated feeling in your abdomen/stomach? & 1 & 2 & 3 & 4 \\
\hline 33. Did you have problems with your clothes feeling too tight? & 1 & 2 & 3 & 4 \\
\hline $\begin{array}{l}\text { 34. Did you experience any change in bowel habit as a result of your disease or } \\
\text { treatment? }\end{array}$ & 1 & 2 & 3 & 4 \\
\hline 35. Were you troubled by passing wind/gas/flatulence? & 1 & 2 & 3 & 4 \\
\hline 36. Have you felt full too quickly after beginning to eat? & 1 & 2 & 3 & 4 \\
\hline 37. Have you had indigestion or heartburn? & 1 & 2 & 3 & 4 \\
\hline 38. Have you lost any hair? & 1 & 2 & 3 & 4 \\
\hline $\begin{array}{l}\text { 39. Answer this question only if you had any hair loss: Were you upset by the } \\
\text { loss of your hair? }\end{array}$ & 1 & 2 & 3 & 4 \\
\hline 40. Did food and drink taste different from usual? & 1 & 2 & 3 & 4 \\
\hline 41. Have you had tingling hands or feet? & 1 & 2 & 3 & 4 \\
\hline 42. Have you had numbness in your fingers or toes? & 1 & 2 & 3 & 4 \\
\hline 43. Have you felt weak in your arms or legs? & 1 & 2 & 3 & 4 \\
\hline 44. Did you have aches or pains in your muscles or joints? & 1 & 2 & 3 & 4 \\
\hline 45. Did you have problems with hearing? & 1 & 2 & 3 & 4 \\
\hline 46. Did you urinate frequently? & 1 & 2 & 3 & 4 \\
\hline 47. Have you had skin problems (e.g., itchy, dry)? & 1 & 2 & 3 & 4 \\
\hline 48. Did you have hot flushes? & 1 & 2 & 3 & 4 \\
\hline 49. Did you have night sweats? & 1 & 2 & 3 & 4 \\
\hline $\begin{array}{l}\text { 50. Have you felt physically less attractive as a result of your disease or } \\
\text { treatment? }\end{array}$ & 1 & 2 & 3 & 4 \\
\hline 51. Have you been dissatisfied with your body? & 1 & 2 & 3 & 4 \\
\hline 52. How much has your disease been a burden to you? & 1 & 2 & 3 & 4 \\
\hline 53. How much has your treatment been a burden to you? & 1 & 2 & 3 & 4 \\
\hline 54. Were you worried about your future health? & 1 & 2 & 3 & 4 \\
\hline 55. To what extent were you interested in sex? & 1 & 2 & 3 & 4 \\
\hline 56. To what extent were you sexually active? & 1 & 2 & 3 & 4 \\
\hline \multicolumn{5}{|l|}{ Answer the following two questions only if you were sexually active } \\
\hline 57. To what extent was sex enjoyable for you? & 1 & 2 & 3 & 4 \\
\hline 58. Did you have a dry vagina during sexual activity? & 1 & 2 & 3 & 4 \\
\hline
\end{tabular}

Suppl. Table 2. Results of the Quality of life and Health Economy Questionnaire 